\title{
SERES MONSTRUOSOS Y CUERPOS FRAGMENTADOS. SUS REPRESENTACIONES EN DOS RELATOS FANTÁSTICOS DE ALBERTO CHIMAL ${ }^{1}$
}

\author{
Virginia Caamaño $M$.
}

\begin{abstract}
RESUMEN
En este estudio se analizan las estrategias formales y discursivas por medio de las cuales se construyen dos textos fantásticos del mexicano Alberto Chimal y se señalan sus rasgos específicos. Se destaca como eje fundamental de los relatos las actuaciones de sus protagonistas, quienes aparecen como monstruos, cuya presencia posibilita la irrupción de lo fantástico, la ambigüedad y lo siniestro.

Palabras clave: literatura latinoamericana, literatura fantástica, cuento y minicuento, ChimalAlberto, monstruos.
\end{abstract}

\begin{abstract}
This study analyzes the formal and discursive strategies through which two fantasy texts by Mexican Alberto Chimal are built, as their specific characteristics are pointed out. The behavior of protagonists is highlighted as a fundamental axis, in light of their presence as monsters that make possible the irruption of the fantastic, ambiguos and sinister.

Key words: Latin American literature, fantasy literature, short story and mini-story, ChimalAlberto, monstrous.
\end{abstract}

¿Qué pasaría si el mundo fuera de otro modo? Alberto Chimal (2006: 9)

La imaginación es una función sin órgano. Georges Canguilhem (1976: 47)

\section{Introducción}

Como he argumentado en varios artículos donde estudio la narrativa breve latinoamericana publicada a partir de la década de los años noventa del siglo XX, es evidente que los autores contemporáneos no están interesados en ajustarse a los estereotipos establecidos tradicionalmente para la literatura del continente. La identidad regional y el compromiso

ML. Virginia Caamaño M. Profesora catedrática e investigadora en la Escuela de Filología, Lingüística y Literatura y en la Maestría en Literatura de la Universidad de Costa Rica.

Correo electrónico: vicaamano@yahoo.com

Recepción: 22- 05- 2013

Aceptación: 12- 07- 2013 
político han quedado atrás, sustituidos por una serie de inquietudes literarias de carácter muy amplio y heterogéneo, según se puede comprobar en los temas, situaciones y personajes que circulan en las obras de las generaciones más jóvenes de escritores y así lo he señalado en otra parte $^{2}$. De manera que cuando en sus producciones hablan de identidad, esta sin duda se refiere a la individual, dado que sus búsquedas son muy personales.

La idea fija y reduccionista de mantener vigente una Latinoamérica "reflejada" literariamente en el realismo mágico, asolada por constantes desastres naturales, golpes de estado, guerras civiles y pobreza eterna todavía persiste en ciertos círculos editoriales y de la crítica, con la consecuente molestia entre autores y autoras que han nacido a partir de la década de los años sesenta, quienes muestran una marcada preocupación por la manera en que sus obras serán leídas, pues las realidades mundializadas plasmadas en ellas son muy distintas de las visiones esencialistas anteriores.

Por este motivo, en su artículo titulado "No quiero que a mí me lean como a mis antepasados" (2004), el peruano Fernando Iwasaki, quien afirma ser "el resultado de una suma de exilios y culturas - peruana, japonesa, italiana y española-" desnuda la clara crisis que afecta al realismo literario tradicional al preguntar: “¿Por qué conformarnos con ser de un solo sitio si podemos ser de todas partes y de ninguna?" Y presenta un listado de creadores del continente, que oscilan entre los 35 y los 50 años de edad, quienes han ambientado excelentes novelas en distintos sitios del planeta y no en Latinoamérica, para defender que "la fantasía y la literatura carecen de fronteras" (cfr. Iwasaki 2004: 120).

$\mathrm{Su}$ aseveración es real, pues las prácticas escriturales producidas en la región son múltiples, abarcan diversos géneros y estéticas reapropiadas ${ }^{3}$ y reescritas por cada artista desde sus propias inquietudes e intereses, donde se evidencian los complejos procesos culturales que se viven en las sociedades actuales y las ricas reflexiones que se realizan a partir de ellos.

Entre esa amplia gama de producciones literarias se encuentra la literatura fantástica, producida por un numeroso grupo de escritores y escritoras en casi todos los países de la región y recibida asimismo, por un público lector que va en aumento, en lo cual incide la popularidad que este tipo de ficciones tiene en los media: el cine -con la construcción de mundos alternativos inspirados en sagas literarias al estilo de Harry Potter y El señor de los anillos, entre otras-, los videojuegos, las historietas y las series de televisión, cuyos argumentos se fundan en la fantasía. Es pertinente, entonces, echar una rápida mirada al surgimiento y desarrollo de esta escritura en el continente y enfocar la atención en uno de sus exponentes más recientes, dos de cuyas creaciones serán objeto de análisis en este estudio.

\section{Productores de lo fantástico en América Latina: el caso de Alberto Chimal}

En América Latina la literatura fantástica tiene una historia importante que se remonta a mitad del siglo XIX. Inicia en Argentina, con las leyendas, relatos y "Coincidencias" de Juana Manuela Gorriti (1818-1892) y las narraciones de Eduardo Wilde (1844-1913) y Eduardo Ladislao Holmberg (1852-1937), quien es el primero en introducir la figura del autómata en las ficciones fantásticas del continente. Oscar Hahn comenta que "los materiales narrativos del cuento fantástico hispanoamericano del siglo XIX provienen de las creencias cristianas, supersticiones populares, ideas filosóficas y debates intelectuales de cada momento históricoliterario. Esto prueba que ni siquiera la literatura fantástica [...] puede desligarse de la realidad en la que fue creada" (1998: 14). 
Como continuadores de esta escritura existe una larga nómina de escritores. Entre los más reconocidos se encuentran los modernistas Rubén Darío (1867-1916), Horacio Quiroga (1878-1937) -durante una de sus etapas-, Leopoldo Lugones (1874-1938) y Amado Nervo (1870-1919), así como los vanguardistas Macedonio Fernández (1874-1952) y Felisberto Hernández (1902-1964) en cuyas obras la extrañeza y el absurdo aparecen como rasgos distintivos de su visión de lo fantástico.

Esta práctica textual alcanza su madurez y gran apogeo con los extraordinarios y reconocidos relatos de Jorge Luis Borges (1899-1986), Adolfo Bioy Casares (1914-1999), Silvina Ocampo (1903-1993) y Julio Cortázar (1914-1984), quienes continúan la reapropiación de la tradición fantástica europea, al establecer otras vertientes, orientadas principalmente hacia lo metafísico o el orden oculto y ambiguo de la realidad, la cual se desestabiliza y desdobla; vertientes a las cuales les infunden nuevos acentos y matices (cfr. Herrero Cecilia 2000).

Algo más tarde, creadoras como Armonía Somers (1914-1994) cuya imagen del mundo real es discordante y perversa; Elena Garro (1920-1998) iniciadora, para cierta crítica, del llamado "realismo mágico"; así como Guadalupe Dueñas (1920-2002), Amparo Dávila (1928) y Carlos Fuentes (1928-2012), cuyas obras surgen durante los años cincuenta y sesenta, son seguidos por autores y autoras de generaciones más jóvenes, entre quienes se encuentran Rosario Ferré (1938), Cristina Peri Rossi (1941), César Aira (1949), Ana María Shua (1951), Daína Chaviano (1960), Fernando Iwasaki (1961), Alberto Chimal (1970) y Claudia Hernández (1975), los cuales continúan enriqueciendo la producción de lo fantástico en el continente y reescribiéndolo, cada quien desde sus propias visiones de mundo y haciendo uso de diversas estrategias para lograrlo.

En atención al interés e importancia que tiene esta literatura, he seleccionado para realizar el presente estudio dos textos fantásticos del mexicano Alberto Chimal, la minificción “Álbum” y el cuento corto "Conejo", incluidos en el cuentario Estos son los días (2005). Interesa determinar en ellos las estrategias formales y discursivas por medio de las cuales se han construido y señalar sus rasgos específicos.

Alberto Chimal es uno de los escritores más productivos y reconocidos de la actualidad, tanto por la calidad de su obra ${ }^{4}$ como por sus prácticas innovadoras ${ }^{5}$. Además de considerárselo un connotado escritor de fantasías en las cuales ha propuesto diversas temáticas que abarcan toda la gama de lo fantástico, incluido lo maravilloso y la ciencia ficción, se lo recomienda como especialista en el tema de la literatura en red debido a su amplia experiencia en ese campo, en el que ha incursionado por medio de distintos proyectos, al tiempo que ha mantenido también, varios blogs literarios. Actualmente, escribe un blog personal, titulado "Las historias", donde comenta sus propias obras -algunas de las cuales pueden bajarse libremente por medio de la web-.

La crítica coincide en señalar que en sus textos se conjugan hechos de la vida cotidiana y actual con situaciones o eventos extraordinarios, relacionando realidad y mito. La estudiosa Lorena Campa lo presenta como un "creador de mundos dentro del mundo y de sutilezas verbales que le permiten traslapar géneros literarios en el espacio de un solo cuento [...]" (cfr. 2006). En su artículo sobre lo fantástico en la narrativa mexicana contemporánea, Javier Ordiz opina que Chimal es el más destacado entre los narradores de relatos maravillosos pues construye "universos propios que funcionan de manera autónoma y con sus propias leyes internas. [...] Con una gran dosis de ironía y parodia, que son ingredientes habituales en toda la obra de Chimal [...]" (2009: 138). 
Al seguir un camino similar al recorrido por otros artistas del continente, como Macedonio Fernández, Julio Cortázar, Agusto Monterroso (1921-2003) y Ana María Shua entre otros, Chimal muestra preferencia por plasmar lo fantástico en minificciones, aunque también utiliza la estructura del cuento moderno, ambas modalidades presentes en los relatos en estudio.

Eje fundamental en la narración de los textos seleccionados es la puesta en escena de lo monstruoso en función del comportamiento de los personajes principales, los cuales parecieran combinar "lo imposible y lo prohibido" (Foucault 2011: 61), posibilitando así la irrupción de lo fantástico, la ambigüedad y lo siniestro, que se intentará mostrar en esta lectura. Son monstruos inspirados en situaciones muy actuales, difundidas a través de los medios de prensa y recreadas en el cine o en series de televisión. Pero antes, conviene dar una mirada sobre la modalidad de cuento y minificción de los relatos seleccionados.

\section{Sobre el cuento y la minificción o minicuento}

Según la crítica venezolana Violeta Rojo, el cuento en sus inicios estuvo relacionado con una variedad de otros géneros y subgéneros -como las tradiciones, las alegorías, las leyendas y otros más- pero con el paso del tiempo esos vínculos se volvieron menos evidentes, al incorporarse en la narración, conformando un género que es reconocido ahora como cuento moderno. El fundamento de ese género reside en su concisión temática y en la intensidad expresiva que pone en el texto los máximos recursos de la lengua, para revelar la imaginación de un narrador individual (cfr. García Berrio et al. 1992). A partir de dicha modalidad se han dado otras mezclas, permitiendo el surgimiento de un subgénero en formación: el minicuento.

Rojo describe la naturaleza de los minicuentos como proteica, en el sentido de que pueden tomar variadas formas genéricas; esto los define pero también los "in-define", por eso los cataloga como "desgenerados" e inclusive llega al punto de dudar del nombre de "cuento" que les ha asignado. Reconoce la facilidad de estas narraciones para establecer relaciones intertextuales, casi siempre de manera paródica y humorística, con diversos géneros como el ensayo, el poema en prosa, la fábula, el bestiario, la parábola, la anécdota, la alegoría, la reelaboración de mitos, así como con otras formas de escritura no literaria, tales como el caso y el chiste. (cfr. Rojo 1995). Al señalar que el lenguaje de los minicuentos debe ser muy preciso, explica que su anécdota comprimida le hace necesario "el uso de cuadros genéricos" o intertextuales, los cuales permiten que el autor brinde más información al lector por medio del esquema narrativo utilizado, según se trate de un mito, una alegoría, un bestiario u otra forma textual (cfr. Rojo 1995: 65).

El estudioso Lauro Zavala, por su parte, las llama "minificciones"7 (cfr. 2000) y las presenta como un género muy nuevo, entre cuyos rasgos específicos se encuentra: el inicio anafórico, un narrador irónico, personajes metafóricos, tiempo fragmentario, espacio elíptico, lenguaje lúdico, un final que no termina la historia y su serialidad (cfr. Zavala 2011). Coincide además con Rojo al señalar su intertextualidad y la manera en que condensa todas las formas de la escritura literaria y extraliteraria de un modo lúdico, que lo convierten en un género proteico.

Por otro lado, la académica Francisca Noguerol se vale de una cita de la escritora argentina Ana María Shua para señalar que las "minificciones tienden en su mayor parte al género fantástico, en parte porque se les exige provocar algún tipo de sorpresa estética, temática o de contenido, ya que el sutil desarrollo de climas o personajes es casi imposible" (Shua citada en Noguerol 2009: 199).

En síntesis y siguiendo lo propuesto por los estudiosos mencionados, se puede decir que esta modalidad de la ficción presenta, entre otras características: una intensa intertextualidad, 
metaficcionalidad, serialidad, tendencia a la ironía y a la parodia y una naturaleza proteica, además de su tendencia a lo fantástico y la necesidad de colaboración activa por parte de quien lee.

Es clara la pertinencia de estudiar este tipo de escritura dada su concisión, su complejidad y su riqueza como forma literaria, la cual está siendo utilizada cada vez más frecuentemente, junto con la del cuento moderno, por artistas del continente.

A continuación se introduce un acercamiento a lo fantástico que ayudará a realizar el abordaje de las narraciones seleccionadas para su estudio.

\section{Acercamiento a lo fantástico}

Durante mucho tiempo la literatura fantástica fue una práctica que no tuvo entrada en el canon culto, según expone el crítico español Javier Ordiz, hasta que: "comenzó a ganar cuotas de atención como objeto de estudio a partir del ya clásico ensayo de Todorov (1970), que sentó las bases por las que han transitado la mayoría de los acercamientos realizados sobre el tema" (2009: 123), y al mismo tiempo, puso en perspectiva la presencia constante y la calidad de este tipo de creación en la literatura occidental.

Desde el conocido aporte de Todorov y a lo largo de más de cuarenta años, estudiosos y críticos han venido intentando identificar y sistematizar la literatura fantástica, con el fin de asignarle su lugar en el canon. Sin embargo, aunque se han realizado trabajos serios y detallados tanto en América como en Europa, no se ha logrado llegar a un acuerdo definitivo sobre la manera más pertinente de clasificar textos tan heterogéneos en cuanto a sus rasgos y características. Para Anna Boccuti tampoco ha habido coincidencia en cuanto a si lo fantástico debe considerarse como género (Todorov 1970), como una lógica narrativa (Bessiere 2001) o como un modo de representación (Jackson 1986). (cfr. Boccuti. 2008). En el momento actual se indaga además, sobre la relación que dichos textos establecen con la realidad, a partir de las diferentes nociones desde las que esta puede ser comprendida.

Dada la variedad de acercamientos sobre el tema, en el presente trabajo se seguirán las propuestas de David Roas en su libro Tras los límites de lo real (2011), donde considera lo fantástico como una categoría estética, un discurso "en relación intertextual constante con ese otro discurso que es la realidad, entendida siempre como una construcción cultural" (2011: 9), de acuerdo con lo cual, "lo fantástico se construye a partir de la convivencia conflictiva de lo real y lo imposible” (2011: 45), por lo tanto, según este autor:

\footnotetext{
[...] al enfrentarnos con las ficciones fantásticas resulta inevitable (y esencial para su funcionamiento) poner en contacto el mundo intratextual y el mundo extratextual (el horizonte sociocultural del lector), pues estas se sustentan en el cuestionamiento de la noción misma de realidad y tematizan, de modo mucho más radical y directo que las demás ficciones literarias, el carácter ilusorio de todas las "evidencias", de todas las "verdades" transmitidas en que se apoya el hombre de nuestra época y de nuestra cultura para elaborar un modelo interior del mundo y ubicarse en él. (Roas 2011: 41-42)
}

Al problematizar la noción única de realidad tal y como ha sido concebida hasta inicios del siglo XX, Roas la enfrenta con los drásticos cambios sucedidos en el paradigma científico a partir de importantes descubrimientos que se dieron en la teoría de la relatividad, la mecánica cuántica, las teorías sobre el cosmos, las investigaciones en neurobiología, los estudios de los filósofos constructivistas, así como la influencia de las nuevas tecnologías de la comunicación, todo lo cual lo lleva a postular dos ideas fundamentales: primero, que la realidad es una construcción subjetiva y segundo, que como tal es compartida socialmente, es una construcción social. Por lo tanto, afirma Roas, "no hay realidad real", solo se conocen representaciones de esa realidad (cfr. 2011: 26). 
Ante tal relativización de la realidad, lo fantástico obliga a que los hechos descritos se confronten constantemente tanto "con la lógica construida en el texto como con esa otra lógica -también construida- que es nuestra visión de lo real". Esas dos realidades no pueden "convivir" de manera que "cuando esos dos órdenes - paralelos, alternativos, opuestos- se encuentran la (aparente) normalidad en la que los personajes se mueven (reflejo de la del lector) se vuelve extraña, absurda e inhóspita" (Roas 2011: 42). Ideas que permitirán determinar hasta qué punto se da la presencia de lo fantástico en los cuentos de Chimal.

Por otra parte, el estudioso Juan Herrero Cecilia considera que lo fantástico moderno tiene relación tanto con la realidad profunda de la vida como con la existencia concreta y puede dar origen al fenómeno de la "inquietante extrañeza", conocido también como lo "ominoso o siniestro"8 (Das Unheimliche) (cfr. Freud 1919) estudiado por Freud, quien señala cómo algunos escritores logran infundirlo en sus narraciones. Dicho fenómeno surge de la irrupción de lo fantástico como "una transgresión de las leyes del mundo ordinario", cuya manifestación podría producir inquietud, fascinación, angustia o miedo en los personajes y en quien lee, al presentarse como ocurrencias reales no explicables de modo racional. Herrero Cecilia (2000) lo llama lo fantástico "existencial": aquello donde se confunden las fronteras entre lo racional y lo irracional, lo vivido y lo imaginado, propio de la experiencia de lo fantástico, aunque según este crítico no debe limitarse sólo a lo tratado por Freud, por lo cual sugiere ponerlo en relación con lo que "no puede explicarse desde los esquemas de la racionalidad y remite a dimensiones más profundas e inexplicables, dimensiones que podemos llamar suprarracionales o supranaturales" (Herrero 2000: 30).

Estas valiosas propuestas facilitarán el acercamiento a los relatos de Chimal y al mismo tiempo, permitirán indagar las realidades de donde han surgido, pues como señala Ordiz sobre lo fantástico:

\footnotetext{
Lejos de ser un tipo de literatura de mero entretenimiento o evasión, nos encontramos ante una tendencia que propone una nueva forma de enfocar la realidad, y que pretende que el lector ponga en duda las bases en que se asienta su estabilidad cotidiana y se plantee preguntas similares a las que formula Alberto Chimal: ¿Qué pasaría si el mundo fuera de otro modo? (Ordiz 2009: 125).
}

En sus textos, Chimal pareciera continuar la senda marcada por Julio Cortázar cuando en la apertura de Historias de cronopios y famas invita a enfrentar el "ladrillo de cristal" que es la realidad cotidiana y abrirse paso hasta el "piso de arriba donde vive gente que no sospecha su piso de abajo" (Cortázar 1989: 12), dando así pie a que lo fantástico irrumpa a través de alguno de esos intersticios misteriosos que desgarran la aparente lisura del ladrillo/realidad, cuyo resultado, según el crítico De León en su comentario sobre la obra de Chimal, es eso fantástico que "maravilla por ser único, pero también horroriza por ser irreversible" (De León 2012). Es lo que se intenta comprobar con el análisis de los relatos seleccionados donde se presenta como rasgo común, según se ha dicho, la puesta en escena de monstruos cuyas conductas inducen a la reflexión sobre su razón de ser literario, al poner en contacto por su medio, según propone Roas (2011), el mundo intratextual con el extratextual.

\section{Monstruos, imposibles y prohibidos}

Entre las varias acepciones que el Diccionario de la Real Academia de la Lengua Española ${ }^{9}$ atribuye a la palabra monstruo se encuentran las siguientes, seleccionadas por su pertinencia en este acercamiento: "1. Producción contra el orden regular de la naturaleza y 5. Persona muy cruel y perversa". De manera que el monstruo responde a una ruptura con el orden 
natural desde la apariencia externa o psicológica de lo considerado "normal" -significado 1y a la transgresión del orden social, moral y legal en función del comportamiento exhibido -significado 5-.

Los dos relatos que se comentan ponen en escena dichos significados pues los personajes protagonistas surgen como seres malvados, cuyas conductas crueles y violentas se oponen a la razón y a la ley y desde esa perspectiva, sus actuaciones pueden juzgarse "antinaturales" o "anormales".

La figura del monstruo ha sido estudiada por intelectuales como Georges Canguilhem (1904-1995) y Michel Foucault (1926-1984), quienes han aportado propuestas muy interesantes que serán de gran valor para llevar a cabo esta lectura.

Para el filósofo Canguilhem (1976) el surgimiento del monstruo "cuestiona la vida, en cuanto al poder que posee de enseñarnos el orden", al hacer dudar de que "lo mismo pueda engendrar lo mismo" haciendo aflorar, por lo tanto, el temor, ya que el monstruo es "lo otro", lo fuera de la norma: "lo montruoso es lo viviente de valor negativo [...] es el contravalor vital. [...] es lo maravilloso al revés, pero maravilloso a pesar de todo"(cfr. Canguilhem 1976).

Su propuesta se podría dirigir tanto a un ser cuya apariencia física es monstruosa como a quien es monstruoso en su comportamiento, al actuar de manera "anormal" o "anómala", condiciones cuyo significado según el Diccionario de la Real Academia de la Lengua Española, señalan la "discrepancia de una regla o un uso" aunque también pueden referirse a "alteraciones biológicas congénitas o adquiridas" por lo demás, "infrecuentes", lo cual destaca aún más su extrañeza.

Entre las investigaciones sobre las diversas formas de alteridad que la cultura ha producido, Michel Foucault ha estudiado "al monstruo humano", una de las tres figuras que constituyen el ámbito de la anomalía ${ }^{10}$. Explica que "la noción de monstruo es esencialmente una noción jurídica -jurídica en el sentido amplio del término, [...] porque lo que define al monstruo es el hecho de que en su existencia misma y su forma, no sólo es violación de las leyes de la sociedad sino también de las leyes de la naturaleza-." (Foucault 2011: 61).

Señala el mencionado autor cómo el monstruo humano llevaba en sí la sospecha de la criminalidad, visión que se va a revertir a partir del siglo XIX, cuando se llega a considerar que "cualquier criminal, [...] bien podría ser un monstruo, así como antaño el monstruo tenía la posibilidad de ser un criminal"(Foucault 2011: 83). Es cuando aparece por primera vez la conducta criminal como patológica ya que el criminal rompe el pacto social y vuelve al estado de naturaleza donde lo que impera es el deseo e interés personal, lo cual lo convierte en un monstruo moral. Se hace necesario, entonces, -y esto sucede a fines del siglo XIX y durante el siglo XX- la organización de un poder médico judicial, conformado por peritos psiquiátricos, tribunales especiales, servicios médico-psicológicos que trabajan dentro de la esfera penitenciaria y otras instancias de vigilancia médico-legal, todas las cuales, según Foucault, determinan el nivel de maldad, de perversidad de los "monstruos". Por lo tanto, la existencia de estos seres es considerada una realidad que ha llevado al establecimiento de toda una gama de mecanismos para mantenerlos bajo control, con el fin de evitar sus actos dañinos.

La conducta de los personajes de los cuentos que se abordarán coincide con algunos de los rasgos mencionados arriba, de ahí que se les pueda considerar monstruos. La protagonista de "Álbum" es una asesina en edad escolar, quien al final acaba con la vida de su propia madre y el narrador de "Conejo", un hombre cuyas actividades podrían incluirlo en la categoría de genocida. La maldad en ellos pareciera surgir como una tendencia intencional de abusar y hacer daño a 
otros seres o personas, pues muestran ausencia de afecto, bondad o compasión y contravienen, en apariencia deliberadamente, los códigos de conducta y moral establecidos socialmente. El mal, señala Víctor Bravo, "es la expresión de una escisión: algo que es a la vez interior y extraño en el sujeto, irrumpe, aflora en el ámbito del yo, para intentar eliminarlo y ocupar su lugar (1988: 75). Como lo fantástico, el mal es una irrupción cuya presencia sitúa a ambos personajes en la categoría de monstruos, cuya conducta pareciera romper los límites de lo real para adentrarse en lo fantástico, de acuerdo con lo indicado por Roas, como se verá en lo que sigue.

\subsection{Monstruos malvados}

\subsection{1 ¿Una niña imposible?}

Siguiendo la denominación que le asigna Lauro Zavala a este tipo de relato ${ }^{11}$ en virtud de su corta extensión, “Álbum” es una minificción. La voz narrativa, omnisciente, utiliza frases cortas y concisas que le dan sentido a la historia y le permite construir imágenes precisas y sucesivas, con las cuales da cuenta de los hechos, sin entrar en mayores detalles. Utiliza de inicio a fin apenas una página, donde el texto no es cortado por ningún punto y aparte. A pesar de dicha brevedad, el paso del tiempo es mostrado en virtud de la secuencia de los sucesos narrados. Estos son transmitidos por la voz narrativa sin juzgarlos o valorarlos de ningún modo, quien lea debe asumir su interpretación.

Para lograr esa eficiencia narrativa, el texto parodia' ${ }^{12}$ una forma extraliteraria, el "caso", narración de un hecho policial o legal supuestamente verdadero. Según Anderson Imbert, en el minicuento, la situación que presenta el caso "puede ser real o fantástica, reveladora del carácter humano y también de la naturaleza absurda del cosmos o del caos" (Imbert citado en Rojo 1995: 73). Sin embargo, Rojo aclara que "ningún minicuento basado en estas formas termina conteniendo enseñanzas morales y sí todo lo contrario" (Rojo 1995: 72); de manera que la función moralizante no es un resultado que se podría esperar de ninguno de los cuentos en estudio y es muy poco frecuente en la literatura latinoamericana actual.

La protagonista anónima del relato es un personaje ausente, cuya presencia domina de manera absoluta la narración como resultado de las consecuencias que sus actuaciones le acarrean a ella, pero sobre todo, a quienes la rodean. Aunque nunca se la nombra directamente y mucho menos se la describe, el posesivo "su madre" permite asumir desde el inicio que se trata de una niña, cuya existencia se conoce por la presencia constante de la figura materna y por los sucesos que provoca. La madre aparece desde la primera frase con el cuerpo escindido, fragmentado, pues es sólo un rostro: "La cara de su madre", la cual es repetida nueve veces a lo largo de la corta narración. Cada vez que esto sucede se produce un desplazamiento en el tiempo y se introduce un nuevo núcleo de actividad conductual por parte de la hija, donde se expone su actuar violento y destructivo.

El título del relato permite asociar la frase de apertura mencionada -"La cara de su madre"- con un álbum de fotografías. A partir de ellas, la persona lectora podría visualizar las transformaciones sufridas paulatinamente en la expresión de esa "cara", producto del desgaste del paso del tiempo y de la angustia y horror que los actos de su hija han marcado, los cuales son enunciados puntualmente por la voz narrativa.

El primer núcleo de actividad conductual muestra las imágenes de lo que la niña destruye de manera indiscriminada con sus actuaciones, a pesar de ser tan pequeña. El 
fragmento es enmarcado por las figuras de la madre -en la apertura- y del psiquiatra -en el cierre-, como representantes de la familia y del aparato represivo que podrían poner coto a esa conducta: "La cara de la madre. La muñeca que arrojó por la ventana. El libro que quemó. La pecera que vació en la sala. La muñeca a la que le arrancó las piernas. Su primer psiquiatra" (Chimal 2005: 11). ${ }^{13}$

Lo que en un inicio se pudo ver como un problema de enojo y rebeldía en la pequeña, continúa empeorando. Esto aleja a sus familiares más cercanos, aislándolas a ella y a la madre: "El tazón con que golpeó a su madre. Su niñera poco antes de marcharse. Su abuela materna poco antes de marcharse. Su padre poco antes de marcharse" (Chimal 2005: 11). La partida de la niñera no pareciera importante al poderse explicar por una serie de motivos relacionados con su situación laboral; la del padre tampoco es especialmente llamativa ya que son numerosos los casos donde, por diferentes causas, ellos hacen abandono de sus familias.

Pero la abuela materna también se va. Es de suponer que su marcha obedece a razones muy graves, las cuales la obligan a romper con una programación social que enseña a las mujeres a ser madres ante todo, con el deber irrevocable de apoyar a sus hijos, sin importar las circunstancias. ¿Cómo se marcha abandonando a su propia hija para que enfrente sola lo que sucede, si se había mantenido junto a ella hasta ese momento? Este acto sugiere impotencia y desesperación ante lo que ocurre, por parte de la abuela. Su hija, por el contrario, sí cumple dicha programación hasta el final de su vida (cfr. Guerra 2006).

La estrategia narrativa permite a quien lee ir identificado en la niña y su comportamiento la causa primordial de todos los abandonos ocurridos, pues según se infiere se ha vuelto difícil y -como se verá-, muy peligroso, permanecer junto a ella. Se perfila así, claramente, la figura de una"niña-monstruo", cuya conducta subvierte la construcción social tradicional que fundamenta los comportamientos en la infancia. En esta, los niños y niñas aparecen como seres esencialmente inocentes, ingenuos y dóciles. Lo contrario indicaría lo anormal, lo monstruoso, tema trabajado en la literatura latinoamericana por notables artistas, como expone Ericka Martínez en relación con algunos cuentos de Silvina Ocampo, donde los niños y las "nenas terribles" "no son inocentes ni salvajes, sino que habitan un margen fantástico desde el que desordenan jerarquías", margen que se convierte en una fuerza perversa (cfr. Martínez 2009: 134) y destructora, similar a la apreciada en el minicuento de Chimal.

Sobre este tema, la crítica Elena Montagud (2011) afirma que "los niños suelen ser representados como figuras angelicales, inocentes, incapaces de provocar ningún daño [...] pero es precisamente en esos territorios asignados a la infancia donde pareciera irrumpir con más fuerza lo extraño y lo siniestro" y así los valora en la obra de Ocampo, donde surgen como agentes del mal. De ahí que, según su opinión, en esos cuentos se da una desmitificación de la figura tradicional de los niños quienes aparecen "corrompidos", con características propias de los adultos, hasta llegar a ser perversos, como sucede con la niña-monstruo del relato en estudio. En los relatos de Ocampo, agrega Martínez: "Las relaciones materno-filiales [...], están siempre manchadas por un deseo de venganza, incesto o muerte". (Martínez 2009: 133).

En "Álbum", la madre aparece como antagonista y víctima de su hija, esta evoca la figura del vampiro, pues le va robando vida y energía a su progenitora, quien recibe y disimula la violencia inexplicable que la niña ejerce desde muy temprano. Una violencia "anormal", donde se muestra que "lo mismo"no engendra "lo mismo", de acuerdo con lo indicado por Canguilhem (1976), al no decirse en la narración que los padres actúen de modo inusual; por lo tanto, la herencia no pareciera ser una posible explicación para los actos infantiles. El abandono 
de los familiares destaca entonces, de modo preciso, la naturaleza anormal de esa conducta y así continúa mostrándolo el texto, al exponer por medio de las imágenes, de modo directo y conciso, la larga serie de actos de abuso y violencia que van en aumento, surgidos sin aparente justificación y dirigidos en contra de todas las personas y seres que rodean a la infante.

La frase "La cara de su madre" encierra la descomposición y el horror expresados en ese rostro y que cada vez será más pronunciado, pues la enumeración de imágenes "fotográficas" que representan los sucesos ocasionados por la niña no deja lugar a dudas: cuando está en su primer kínder ${ }^{14}$ es abandonada por su primer psiquiatra, mete el gato al horno, llega un segundo psiquiatra, patea a un compañero, corta la trenza de una niña, tiene un tercer psiquiatra, corta la cara de otra niña y pasa a un cuarto psiquiatra. En el segundo kínder destripa a un perro, quiebra el brazo de su madre, también el brazo de su maestra y el de su quinto psiquiatra. Al llegar al tercer kínder arranca un trozo de la oreja de un niño y hay una primera denuncia en su contra. El paso de un kínder a otro se deduce como resultado de ser expulsada del anterior. Durante esta etapa se menciona el bolso y la tarjeta de débito de su madre. Cuando debe ingresar a primaria, surgen las imágenes de los dos directores que no la admiten y del tercero que la acepta ${ }^{15}$, pero cuando trata de ahogar a una niña en el excusado y empuja a otra por las escaleras, los padres de familia escriben una carta en su contra. Esto implica que no la reciben más y el director de una segunda primaria la admite. Ahí se habla del suéter de un compañero desaparecido y luego del cuerpo de ese niño. La patrulla la va a buscar y madre e hija huyen (cfr. Chimal 2005).

Durante este tiempo, además de ser testigo privilegiada y receptora de tal violencia, la madre es también codependiente en ese círculo terrible, al obedecer, como se explicó, una programación cultural que enseña a las mujeres a resguardar a sus hijos bajo cualquier circunstancia, porque son "carne de su carne" aunque como muy bien señala Kristeva: "el hijo, él o ella, es irremediablemente otro" (Kristeva citada en Guerra 2006: 164). Esta mujer, sin embargo, se sacrifica y es sacrificada por no apartarse de su prescrito rol, el cual cumple, literalmente, hasta su misma muerte, ya que protege a la hija a pesar de todo hasta el final, que es su propio final. Con esto, convoca a quien lee a ponerse en su lugar y preguntarse si habría actuado de igual manera.

En su fuga, ambas mujeres se esconden, consecutivamente, en tres moteles. El primero se incendia -presumiblemente por acción de la hija- y las autoridades publican un boletín con la foto de la madre, responsable como adulta por la conducta de la menor. En el segundo aparece un bebé -cuya presencia no es explicada en el texto ${ }^{16}$ - del cual se dice "que resistió tres días" (Chimal 2005: 11). De nuevo se sugiere, en vista de su historial, que la hija lo asesina pues el término "resistió" implica sufrimiento, provocado por algún tipo de tortura o enfermedad.

En el tercer motel surge por fin, en primer plano - no de modo lateral como las veces anteriores-, la agresión centrada en la madre, al mostrarse por medio de la voz narrativa lo que el álbum fotográfico revela: "El teléfono que su madre trató de usar. La cara de su madre. Un ojo de su madre. La lengua de su madre. El otro ojo de su madre" (Chimal 2005: 12) Se perpetra así el matricidio y la sensación de lo siniestro, que se había venido estableciendo conforme avanzaba el relato se posesiona de este, al evidenciarse la amenaza irremediable proveniente de alguien tan familiar, cercano y supuestamente amoroso como puede ser la propia hija, al mismo tiempo que surge el cuestionamiento sobre la posibilidad real de que esto suceda. Ciertamente, un inquietante temor alcanza a quien lee, al imaginarse que pudiera ocurrirle un suceso tan horroroso con su propia descendencia.

En su artículo "El escalofrío en la última minificción hispánica: Ajuar funerario, de Fernando Iwasaki”, la crítica Francisca Noguerol (2009: 208) comenta la crueldad infantil 
en una serie de cuentos de varios autores ${ }^{17}$ y señala que la inquietud y el miedo son más marcados cuando los victimarios son los niños, pues se rompe la idea de la bondad e inocencia intrínsecas del período de la infancia. El horror que provocan los sucesos de "Álbum" se hace más efectivo por la forma concisa y directa de la narración, donde se confunden las fronteras entre lo racional y lo irracional, lo real y lo irreal, propios de la experiencia de lo fantástico, como apunta Herrero Cecilia (2000) y que además, como señala De León (2010), "horroriza por ser irreversible".

Demostrando una crueldad extrema, a la hija victimaria no le basta con quitarle la vida a su progenitora y como si quisiera castigarla por algún motivo desconocido - ¿tal vez por cuidarla hasta el final o simplemente por haberle dado la vida?-, despedaza con saña su rostro, separado desde el inicio del relato del resto del cuerpo, ya que de este solo se han visto dos "fotografías": "el brazo en cabestrillo de su madre" y "Un hombro desnudo de su madre"18 (Chimal 2005: 11) donde hay, probablemente, una herida o un golpe-. La fragmentación del cuerpo materno, centrada desde el inicio en su cara, se hace efectiva de un modo hiperrealista en ese momento de su muerte.

La presencia de un "primer psiquiatra" como anuncio de otros que intentarían ayudar a madre e hija en las situaciones descritas, dejan en evidencia la incapacidad de las diversas instancias para controlar a la infante, induciendo al que lee a preguntarse si esto es posible. Ante los sucesos enumerados, "la (aparente) normalidad en la que los personajes se mueven (reflejo de la del lector) se vuelve extraña, absurda e inhóspita" (Roas 2011: 42) colocando a dicho lector ante lo fantástico.

Aparatos ideológicos de estado ${ }^{19}$ como la familia y la escuela, no logran controlar a la niña a pesar de algunos intentos, los cuales se evidencian cuando la voz narrativa habla sobre: "El rincón en el que estuvo castigada"; "El niño que la golpeó" y "La silla a la que fue atada"(Chimal 2005: 11), o se refiere a los varios directores de kínder y de primaria que no la admitieron en sus centros educativos o la arrojaron de ellos. Igualmente, la reacción de los otros padres de familia, por medio de quejas, cartas o denuncias en su contra, tampoco la detienen en sus actos de violencia y destrucción. Tales castigos no dan resultados y no es posible hacer de ella una niña "normal", a lo cual tampoco contribuyó la madre.

El fracaso del aparato represivo representado por los cinco psiquiatras, tampoco es explicado en el texto. A pesar de su presencia como expertos en el tema de las enfermedades mentales, su aparente falta de determinación para actuar ante la conducta de la protagonista -quien más bien los agrede y victimiza-, deja la duda sobre una posible dolencia de esa índole. Según Foucault, cuando existen elementos que pueden verse como demencia o como crimen: "En sí mismos, como maldad ${ }^{20}$, como perversidad, como trastornos diversos, como desorden dentro de la familia, funcionan por ello como síntomas de un estado patológico que requiere internación. Son en sí mismos una razón para intervenir" (Foucault 2011: 143). Sin embargo, en este caso, los psiquiatras no intervienen.

Aunque es frecuente la creencia en la maldad como patología, existe también en ella una parte incomprensible que no ha sido posible explicar. Por eso afirma Foucault, cuando se observa que la persona desde muy niña ha actuado con maldad se va a considerar que no existe nada patológico en ella pues "toda su vida, desde lo más recóndito de su infancia, se parece al crimen" (2011: 280). En ocasiones, como sucede en esta minificción, no se enuncia una relación de causa/efecto ni otra motivación, que permita explicar racionalmente lo sucedido.

El minicuento se cierra sin que la policía haya logrado atrapar a la criminal. Es urgente que lo consiga, porque en el final, el narrador continúa mostrando fotografías con los resultados 
de las acciones perpetradas por ella: "El coche del hombre que la recogió en la carretera. La primera comentarista que habló de ella en la televisión. El coche del segundo hombre que la recogió en la carretera" (Chimal 2005: 12). Lo siniestro se mantiene en este final contundente, donde se muestra que la niña sigue libre y su libertad significa un peligro mortal para todos los que tengan la mala fortuna de encontrársela.

El límite entre lo posible y lo imposible en esta narración es muy ambiguo, aunque podría decirse, siguiendo a Roas (2011) que en ella se da una convivencia conflictiva entre lo real y lo imposible a partir de la puesta en circulación de la maldad. ¿Podría existir una niña así? En la vida real no se habla mucho de esto, aunque en los media ${ }^{21}$ cada vez se subvierte más el estatuto de supuesta inocencia asignado a la infancia y este minicuento es la parodia de un "caso" policial que expone tales sucesos. En cuanto a la literatura fantástica del continente, como se muestra en algunas creaciones - de Silvina Ocampo, Armonía Somers, Fernando Iwasaki y Pía Barros, entre otros-, no sería el primer caso en el cual se escenifiquen este tipo de situaciones, donde el sentimiento de lo siniestro "no puede explicarse desde los esquemas de la racionalidad y remite a dimensiones más profundas e inexplicables, dimensiones que podemos llamar suprarracionales o supranaturales" (Herrero 2000: 30), como se verá también en el cuento siguiente.

\subsubsection{Un narrador perverso}

"Conejo" es un cuento corto, de un poco más de dos páginas de extensión. Comienza in medias res y es narrado de principio a fin en primera persona, por un protagonista anónimo. Este, por medio de un lenguaje coloquial y un discurso confesional y manipulador, justifica los actos que lleva a cabo y cuenta después, en detalle.

El discurso inicial deja en evidencia la intención del protagonista de ganarse la voluntad, simpatía y aprobación hacia él y su conducta, por parte de quien lee. Para ello, expone sugestivamente sus puntos de vista sobre el perjuicio que ocasionan los conejos dondequiera que van. Al hacerlo, enfatiza y repite algunos términos de manera que sus palabras sean aceptadas sin discusión, pues lo que dice es, supuestamente, una verdad que todos conocen y deberían compartir:

\footnotetext{
No tengo nada en contra de ellos como personas, es decir, si se puede hablar así de los conejos.

Pero son demasiados. Y dañinos. Está en su naturaleza. Todo el mundo lo sabe. Si se les deja libres en cualquier sitio, y quiero recalcarlo; en cualquiera, empiezan a multiplicarse. Como conejos. Por eso decimos así y no decimos como cucarachas o como otro animal.

Y si se les deja multiplicarse, al poco tiempo se vuelven miles, y millones, y cuando ya no tienen qué comer, empiezan a quitarnos la comida. No respetan nada. Nada les importa.

Y ni siquiera deben ser muchos para empezar. Australia, por ejemplo, se arruinó por dos conejos que alguien dejó allá. Dos conejos. En poco tiempo no había espacio para nadie, no había plantas, no había nada. Todo apestaba porque estaba lleno de excrementos...

No es ningún secreto. (Chimal 2005: 71) ${ }^{22}$
}

Los argumentos expuestos le permiten al narrador presentar, distendidamente, lo que cree una obligación ¿moral? y un derecho para imponer su curiosa visión de mundo, en defensa del futuro de la humanidad. Se apoya con certeza en un supuesto "deber ser" y en ciertos "valores" comunes, autoasignándose la representación de una dudosa mayoría la cual -según su opinión-, no actúa ante los peligros denunciados porque no tiene suficiente claridad en sus ideas, ni decisión para hacer lo correcto, o porque cree en "cosas bonitas" -como la defensa de los derechos humanos o algunas enseñanzas del cristianismo- que considera imposibles de conseguir: 
Y mucha gente habla de la convivencia, de poner la otra mejilla, de todas esas cosas tan bonitas, pero yo, por lo menos, no me puedo quedar cruzado de brazos.

Dicen que el hombre común es impotente, que no puede hacer nada pero no es cierto. Claro que puede. Es verdad que nadie puede cambiar sin ayuda todo lo que está mal en un momento dado, y por eso la gente se desanima. Pero si todos hacemos nuestra parte..., si ponemos nuestro grano de arena, como se dice... (Chimal 2005: 71)

Para realizar su cometido, el narrador no menciona la posibilidad de controlar la población de conejos -si fueran realmente tan dañinos- por medios como la esterilización u otra posible solución, racional y humanitaria, sino que ha tomado decisiones drásticas y finales al verlos como una alteridad amenazante. Así, confiesa abiertamente y sin escrúpulos: "me dedico a matar conejos. Matarlos: tampoco creo en cárceles ni nada así. No me hago ilusiones. Los mato de uno en uno, porque no tengo muchos recursos y no puedo hacer como yo quisiera, es decir, envenenarlos por millones con algún gas, o arrojarles bombas...” (Chimal 2005: 71). El título del cuento con el nombre en singular indica el lugar absoluto y persistente que cada conejo ocupa en la mente del narrador, pues para él, cada uno es apenas un eslabón de una cadena sin fin.

Si como afirma Roas, los hechos descritos en los textos fantásticos son confrontados constantemente por quien lee, tanto "con la lógica construida en el texto como con esa otra lógica -también construida- que es nuestra visión de lo real” (Roas 2011: 42), ¿cómo no considerar fantástica la extraña disposición del narrador contra esos seres, que aparecen con un carácter tan ambiguo en el cuento?

Porque desde el inicio, el narrador les otorga a los conejos un carácter humanizado al llamarlos "personas" y acto seguido indica las supuestas características propias de su "naturaleza", que considera catastróficas para la humanidad. La unión de ambas percepciones sobre esos animales permite "la irrupción de lo anormal en un mundo en apariencia normal" (Roas 2011: 107), introduciendo así una perspectiva irreal del mundo. Pero no se queda ahí.

El texto traspasa también los límites de lo real y racional e ingresa en la irrealidad cuando el hablante limita sus actividades cotidianas a la lucha por la anhelada eliminación física de los conejos, de manera que esta aparece como su única preocupación y trabajo, dada la minuciosidad ejercida y el tiempo que ella debe consumirle. Su labor se inicia con la localización de un conejo: cuenta cómo lo sigue, averigua su dirección, lo vigila hasta conocer sus hábitos y una vez que lo ha tomado prisionero, lo lleva a su casa y en "el cuarto especial, con todas las puertas y ventanas cerradas y la música a todo volumen [...] le hago saber que va a ser ejecutado y le explico por qué. De este modo no llega nunca a pensar [...] que sólo quiero "jugar" o que tengo motivos personales"(Chimal 2005: 72).

La irrealidad de la situación se hace aún más evidente cuando el hombre explica su método y resultados esperados: "Y no lo hago rápido: tengo que ser lento porque no tiene sentido que mueran de otro modo. Si sufren [...] los conejos que sobreviven se horrorizan y aprenden a temernos. Esto es muy importante aunque suene terrible. Yo no niego que lo sea. A mí no me gusta. Pero debe hacerse" (Chimal 2005: 71-72). De manera que los conejos no sólo parecieran tener conciencia de su situación y comprender las amenazas del narrador, sino también la capacidad de "aprender" a tenerle miedo.

A partir de estas confesiones y siguiendo a Roas (2011), el mundo de "Conejo" puede proponerse como un orden paralelo, alternativo, donde se establece un choque entre realidad e irrealidad en vista de que los conejos aún siendo animales -en virtud de lo argumentado en 
primera instancia por el narrador- también poseen características humanizadas, al atribuírseles por ejemplo, la capacidad de hablar y tener sentimientos filiales.

Siguiendo lo expuesto por el protagonista, sus odiados enemigos se expresan racionalmente, tienen familia constituida y se relacionan con ella. Viven en una dirección determinada, parecieran moverse en el mundo como lo hacen los humanos, poseen sentido de propósito y mantienen hábitos cotidianos. Exactamente como la gente. Pero son conejos. Dadas las reglas alteradas que lo gobiernan, ese mundo se presenta, indudablemente, como fantástico y así habría que verlo. No es una alegoría, como podría en algún momento pensarse, de modo que cuando el hombre habla de conejos, esto no debiera entenderse como metáfora de personas, sino textualmente: se refiere a conejos.

Desde el discurso emitido por la voz narrativa, los conejos aparecen como una alteridad amenazante y extraña, dentro de la cual, en cualquier momento, podría introducir también a personas verdaderas, provenientes de culturas, etnias o estratos sociales distintos a los suyos; o a personas de otro género o con prácticas sexuales alternativas, a quienes podría someter a procedimientos similares a los que impone a los odiados animales. Porque cualquiera que no sea el protagonista podría verse en el lugar del "conejo", de repente incluido en el discurso de odio, disfrazado de otra cosa, con que los enfrenta y extermina, al considerarlos peligrosos para su idea trastocada de lo que debería ser el mundo - sin haber dado pensamiento, aparentemente, a la cultura de depredación que imponen los seres humanos dondequiera que están-. Todo esto vuelve aún más siniestra, temible y malvada la conducta de ese hombre, incapaz de sentir culpa o arrepentimiento por lo que hace.

Dado lo anterior, parece válido entender que desde su distorsionada visión, el narrador pretende llevar a cabo una especie de "genocidio" en contra de los "humanizados" conejos, entendiendo por genocidio ${ }^{23}$ los: "actos perpetrados con la intención de destruir total o parcialmente a un grupo nacional, étnico, racial o religioso como tal" ${ }^{24}$. Concepto que engloba claramente las intenciones del narrador, porque su blanco son los curiosos animales/personas del relato.

En la lectura propuesta en este estudio se considera que a pesar de tratarse de conejos, la ideología y los actos que sustentan el proceder del personaje actualizan el camino recorrido por la humanidad, que la ha llevado del darwinismo social a la eugenesia y del racismo a la limpieza étnica, fundamentándose en una vergonzosa pseudociencia. Uno de los capítulos más tempranos y brutales de genocidio es el ejecutado por los conquistadores y colonizadores europeos contra los habitantes de América, pues estos no cumplían con los paradigmas étnicos y culturales de Occidente. Es un tipo de ideología cuyo discurso, aún vigente, ha justificado numerosos crímenes, perpetrados a lo largo de la historia contra personas consideradas "otros" por sus verdugos y que Chimal visibiliza con ironía, al ponerlo en boca del protagonista del cuento, dirigido contra los conejos. Desnuda de ese modo los alcances que tienen, tanto el discurso como su práctica y la mentalidad de quienes los profesan.

Así, el narrador cuenta con orgullo, expresándose fríamente y en tono seguro, los pasos que sigue para adueñarse del conejo y reducirlo a ser solamente un cuerpo, del cual dispondrá a su gusto. En su exposición, evita hacer referencia al horror y sufrimiento de cada animal en particular, pues eso no le importa. Lo diseccionará estando aún vivo, con la intención de escarmentar a los sobrevivientes. Los cuerpos despedazados aparecen entonces no como partes reales sino como simulacros ${ }^{25}$, despojados de cualquier carga espiritual o emocional, destruidos sin piedad por quien ejerce su poder sobre ellos. 
Muy seguramente, el carácter y atroces actos cometidos por el narrador inspirarán extrañeza, rechazo y espanto en las personas lectoras, por imponer sus ideas y deseos por medio de la violencia, sin mostrar ninguna duda ni contrición. Seguro de tener la razón, y satisfecho por ejercer el poder brutal que sus medios le permiten, no es capaz de cuestionar, en ningún momento del relato, sus acciones. De acuerdo con lo expresado por Roas, este tipo de personajes "dan miedo porque matan o, al menos, suponen una amenaza para la integridad física de los personajes con los que se enfrentan" (Roas 2011: 95), aunque se trate de animales. Pero además, por que convocan el sentimiento de lo siniestro en virtud de lo rutinario de esas acciones y la manera fría, organizada y metódica en que las realiza:

es largo, muy tedioso y, francamente, muy desagradable. Muchas veces debo repetirme que es necesario.
Creo que no lo hago mal, sin embargo. Por ejemplo, puedo sacar huesos enteros sin hacer más que un
corte o dos, puedo desprender grandes pedazos de piel sin que se rompan...
[...] Cuando he terminado tengo lo siguiente: por un lado el tórax, por otro lado lo que está dentro del
tórax, por otro más todo lo que está conectado con el tórax. Entonces corto todas las articulaciones, pongo
aparte cada trozo y me ocupo de la cabeza: la rasuro toda, hasta las cejas y las pestañas; arranco todos
los dientes; saco los ojos y la nariz. Por último tomo las fotos; uso una película de 35 milímetros. Cuando
termino tiro todos los restos al tanque del ácido y me voy al cuarto oscuro a revelar las fotos. Cuando
termino allí, el tanque ya está listo para vaciarse, y lo vacío. (Chimal 2005: 72)

Al exponerse desde su propia voz, este protagonista surge como un monstruo que no solamente es malvado, sino también perverso, ya que al hacer el mal lo disfruta, mientras trata de presentar lo malo como bueno y peor aún, como necesario. Es un ser que no cree en los derechos de las personas y mucho menos consideraría los de los animales. Así lo enseña al declarar que luego de matar un conejo, lo que más le gusta es "inmediatamente después, [...] comenzar de nuevo; buscar otro conejo, seguirlo, averiguar su dirección, vigilarlo hasta conocer sus hábitos"(Chimal 2005: 73).

Como en el cuento anterior, se presenta la fragmentación de cuerpos, aunque en esta ocasión se trate de un conejo. Según Nicole Sault "In our everyday language we reduce people to body parts, referring to individuals in terms of particular anatomical segments -brain, breasts, genitals, heart, legs, and so on". (Sault 1994: 6). Foucault ha enseñado que el cuerpo, además de ser un texto cultural es también un sitio de control social, regulado, sujetado, transformado y mejorado por los poderes, los cuales le marcan un deber ser y lo convierten en un "cuerpo dócil", "manipulable" (cfr. Foucault 1980). Esto se logra trabajándolo en sus partes (cfr. Foucault 2005), como hace el narrador con cada animal, al desmembrarlo.

El voyerismo enfermizo y la necesidad de documentar fotográficamente crímenes de esta índole son parte de la puesta en escena de esos cuerpos despedazados, que como tendencia dominante en el imaginario cultural de Occidente durante las últimas décadas del siglo XX, ha sido estudiada por académicos e intelectuales de distintas disciplinas, entre ellos el historiador del arte Juan Antonio Ramírez, quien opina que:

[...] durante la época contemporánea se ha vivido la experiencia del despedazamiento corporal a una escala verdaderamente gigantesca. Los accidentes mecánicos, la tecnología bélica orientada a la producción de grandes explosiones, así como la experimentación biológica y la cirugía generalizada, han permitido a los hombres de las últimas generaciones conocer de cerca más cuerpos fragmentados que en toda la larga historia precedente de la humanidad. (Ramírez 2003).

La descripción realizada por el anónimo narrador continúa evocando escenas mostradas en los media, donde cuerpos fragmentados y cadáveres aparecen con cotidiana abundancia. Asimismo, en las populares series televisivas sobre hospitales, donde se expone y 
trivializa una variada gama de intervenciones quirúrgicas, que despierta una mínima reacción en el público, impávido ya ante la constante exposición de órganos abiertos y la presencia de la sangre. Por eso Giddens (2002) indica que en la época actual: "se llevan a cabo muchos procesos de "permeabilidad" en los cuales el conocimiento técnico, de una u otra manera, es reapropiado por las personas profanas que lo aplican rutinariamente en el transcurso de sus actividades cotidianas." (2002: 137).

No es de extrañar por lo tanto, que el protagonista del relato, supuestamente una de esas "personas profanas" -aunque en el texto no se indique otro oficio además de sacrificar conejos-, sea capaz de viviseccionar de modo tan atroz y como práctica ritualizada los cuerpos de los animales que ha capturado, solazándose en describir las técnicas utilizadas, con lo cual naturaliza tanto su discurso, como esas prácticas de disección anatómica que lleva a cabo.

La voz narrativa aduce que su proceder no implica "nada personal" contra los conejos, a pesar de su ensañamiento obsesivo con un conejo por vez y del discurso de odio que acompaña sus acciones. Esto convierte todo el evento en algo verdaderamente personal y reafirma aún más su carácter de monstruo, el cual es según Canguilhem (1976) "lo viviente de valor negativo", un "contravalor vital", que tal como se presenta en el cuento disfruta cortando vidas. Por su parte, Roas explica que el monstruo surge como "algo que está más allá del orden natural, es lo "otro", lo no humano" (2011: 89). Así se presenta el personaje en cuestión, quien al igual que otros monstruos criminales, padece de un yo exacerbado que se manifiesta en su conducta ególatra y narcisista, dadas su arrogancia e imposibilidad para reconocer las necesidades de otros seres o personas.

Ejemplo de ello se da cuando un conejo joven le pide clemencia reprochando su conducta y al no conseguir compasión por su parte, lo llama "Hijo de tu puta madre". El narrador confiesa que "esas palabras de odio tan inesperadas, tan incomprensibles, me alteraron tanto que lo rematé en ese instante, a pesar de que no íbamos ni a la mitad del procedimiento" (Chimal 2005: 72). A pesar de la frialdad demostrada, su intolerancia ante la crítica le hace perder totalmente el control y renunciar al placer que le causa aplicar la tortura al conejo. Su incapacidad para ver los sentimientos de los otros, unida a su propia necesidad de ser reconocido y admirado por una labor que considera heroica, producto de su perseverancia, paciencia y dedicación, son prueba de esto. Por eso sueña con que sus acciones sean celebradas como las "grandes hazañas, las que salen en la televisión y los periódicos, por igual en tiempos de guerra que de paz... y reconozco que hay mucho de vanidad en esto"(Chimal 2005: 73).

Su confesión anónima y su discurso manipulador son un intento por lograr un poco del reconocimiento esperado. Sin embargo, la realidad alternativa y fantástica descrita en el relato es regida por sus acciones crueles y despóticas, que permiten la irrupción del sentimiento de lo siniestro a lo largo de la narración. Al exponerse a sí mismo por medio de su monolítico discurso, este narrador anónimo se ha descubierto ante los ojos de quien lee. No se puede evitar considerarlo un monstruo perverso.

\section{Lo siniestro hasta el final}

En la literatura fantástica actual según Roas "lo que está ausente [...] es el miedo que experimentan los personajes, pero no la impresión inquietante sobre el receptor" (2011: 103), lo cual se comprueba en los relatos estudiados, en cuya conclusión se postula que los protagonistas continúan ejerciendo su función de monstruos criminales, pues hasta entonces nadie los ha 
detenido. Los cuerpos de sus víctimas, mutilados o no, son resultado del encuentro entre lo real y lo irreal, donde lo familiar se ha convertido en siniestro y produce miedo porque no se comprenden las razones de lo que sucede.

Al darse la "convivencia conflictiva de lo real y lo imposible" (Roas 2011: 45) como es el caso de las historias y personajes en los cuentos de Chimal, se pone en duda lo considerado real y posible, al descubrirse que después de todo, "nuestro mundo no funciona como creíamos." (Roas 2011: 107).

\section{Notas}

1. El siguiente es el resultado parcial del proyecto de investigación "Narrativa breve latinoamericana de las dos últimas décadas: reescritura de lo fantástico en una selección de cuentos de Claudia Hernández y Alberto Chimal”, inscrito en la Vicerrectoría de Investigación con el N021-B2-166.

2. Ver mis artículos "Máscaras de una identidad oculta. Una lectura de “'Señales captadas en el corazón de una fiesta" de Rodrigo Fresán". Revista de Filología y Lingüística. 38 (2); "Memorias del desaliento. Acercamiento a dos cuentos cubanos contemporáneos: “"Huracán” de Ena Lucía Portela y "La yerba atrae a los tiburones" de Michel Perdomo". Revista Estudios. №25; “"'Héroes sin futuro”. Aproximación a "Deambulando por la orilla oscura" de Alberto Fuguet". Revista de Lenguas Modernas. N¹7; "De ciudades y pasiones. Un acercamiento a cuatro cuentos latinoamericanos del fin de siglo". Revista de Filología y Lingüística. 36 (1); "Enfrentamientos y rebeliones en un microcosmos urbano: historias de ascensor". Revista de Lenguas Modernas. $\mathrm{N}^{\circ} 11$; "Rumores del presente: revelaciones y pequeñas historias. Un acercamiento a "Santa Narcótica" de Cristina Civale y "El tibio atajo de la paz" de Naief Yehya". Revista de Lenguas Modernas. $\mathrm{N}^{\circ} 8-9$.

3. En el sentido que le adjudica Erna von der Walde: "sacarlas de su lugar de origen y reubicarlas en otro contexto" (cfr. versión digital).

4. Es uno de los pocos autores incluidos en las cuatro antologías generacionales más importantes publicadas en su país Generación del 2000 (2000), Novísimos cuentos de la República Mexicana (2005), Nuevas voces de la narrativa mexicana (2003) y Grandes Hits Vol. 1. Nueva generación de narradores mexicanos (2008). Algunos de sus cuentarios son: El país de los hablistas (2001); Estos son los días (2004); Grey (2006); La ciudad imaginada y otras historias (2009); 83 novelas (2011); El viajero del tiempo (2011) y El último explorador (2012). Ha publicado varias novelas y realizado traducciones literarias.

5. En una entrevista realizada por Ernesto Priego para el blog "\#Sin lugar. Espacio ni de aquí ni de allá" (2010). Chimal señala que su trabajo en la red es como cualquier otro: "Hace tiempo que no me es posible trazar una división clara entre "en línea" y "fuera de línea". En especial en años recientes, mucho de lo que he hecho en línea se ha convertido en el origen de varios proyectos" Por medio de esa tecnología colabora en varias revistas, ha publicado algunos libros y mantiene un blog literario y una cuenta de Twitter. (cfr. En: http://sinlugar2010.wordpress.com/2010/08/20/alberto-chimal-entrevistadivagaciones/)

6. Se le puede encontrar en: http://www.lashistorias.com.mx

7. Zavala reúne alrededor de 200 nombres distintos que escritores, críticos y lectores han dado a esas ficciones, los más utilizados son minicuento, minificción, microficción y cuento hiperbreve, pero según su opinión el término minificción los abarca de la mejor manera a todos. (cfr. Zavala, versión digital, 2011). En este estudio se utilizará indistintamente los términos minificción o minicuento para hacer referencias a estos textos.

8. Visto como algo que debía mantenerse oculto y se ha manifestado. Es lo familiar de donde repentinamente surge algo que se encontraba reprimido, volviéndose amenazante, causando extrañeza, inquietud, angustia o miedo. (cfr. Freud. 1981. Tomo III: 2483-2505). A partir de la interpretación de ese texto de Freud, Roas señala que "La literatura fantástica saca a la luz de la conciencia realidades, hechos y deseos que no pueden manifestarse directamente porque representan algo prohibido que la mente ha reprimido 
o porque no encajan en los esquemas mentales al uso y, por tanto, no son factibles de ser racionalizados. Y lo hace del único modo posible, por vía del pensamiento mítico, encarnando en figuras ambiguas todo aquello que en cada época o período histórico considera imposible (o monstruoso)" (Roas 2011: 32).

9. Todas las consultas al Diccionario de la Real Academia de la Lengua Española se han hecho en la versión digital.

10. Las cuales según sus hallazgos, se empiezan a definir en el siglo XVIII y se introducen ya en el siglo XIX. Las otras dos figuras son "el individuo a corregir y el niño masturbador" (cfr. Foucault 2011: 61).

11. Indica Zavala que esta modalidad es un género reciente, experimental y complejo surgido en Hispanoamérica durante la primera mitad del siglo XX. Para Anna Boccuti la corta extensión de estos textos es sólo uno de los factores que inciden en su posible clasificación, al afirmar que ellos "no aceptan encasillamientos o etiquetas". Coincide con Zavala en considerarlos de naturaleza híbrida (Cfr. Boccuti 2008: 224).

12. Parodia desde la noción establecida por Genette de "Parodia mínima" la cual considera "la forma más rigurosa de parodia" y que: "consiste en retomar literalmente un texto conocido para darle una significación nueva, jugando si hace falta y tanto como sea posible con la palabras" (Citado en Rojo 1995: 73).

13. A partir de aquí, todas las citas de "Album" y "Conejo" son del cuentario Estos son los días. México: Ediciones Era, 2005.

14. La edad de ingreso al kinder varía de lugar en lugar. En México es a los 3 años.

15. Podría interpretarse que la madre le paga, con su tarjeta de débito para que acepte a su hija en la escuela.

16. Sugiere la colega Mariela Romero que el niño es resultado del embarazo materno, al haberle "pagado" la madre con relaciones sexuales al director de la segunda primaria que acepta a la hija. Esto explicaría también una de las "fotografías" de la madre, donde se muestra su "hombro desnudo".

17. Entre los ejemplos que presenta están cuentos de Fernando Iwasaki, Pía Barros, Ana María Matute y Espido Freire (Cfr. Noguerol 2009).

18. Ver cita 16 .

19. Siguiendo las propuestas de Louis Althússer (1918-1990) en: Ideología y aparatos ideológicos de estado (1969).

20. Foucault estudia cómo durante el siglo XIX se da una "batalla jurídico psiquiátrica alrededor de la maldad infantil", de manera que "La infancia fue el principio de generalización de la psiquiatría; tanto en ésa como en otros lados, la infancia fue la trampa para los adultos" (2011: 280-281).

21. Véase por ejemplo la serie "Criminal minds" y algunos episodios de las series "CSI".

22. Los destacados en las citas son del texto original.

23. El crimen por Genocidio es establecido por el Alto Comisionado de las Naciones Unidas para los Derechos Humanos, artículo II, en un documento que entra en vigor el 12 de enero de 1951 y por el Estatuto de Roma de la Corte Penal Internacional, artículo 6, en otro documento que rige a partir del $1^{\circ}$ de julio de 2002. Entre las acciones que se consideran genocidio están: a) Matanza de miembros del grupo; b) Lesión grave a la integridad física o mental de los miembros del grupo; c) Sometimiento intencional del grupo a condiciones de existencia que hayan de acarrear su destrucción física, total o parcial; d) Medidas destinadas a impedir nacimientos en el seno del grupo; e) Traslado por fuerza de niños del grupo a otro grupo.

24. Disponible en: http://www2.ohchr.org/spanish/law/genocidio.htm

25. La intervención discursiva e imaginaria sobre los cuerpos ya no se limita solo al cuerpo humano, "natural", ya que en el discurso de la ciencia ficción abundan los cyborgs, seres en los cuales se diluyen los límites de la corporalidad al ser en parte humanos y en parte máquinas. Tema que no es pertinente en este trabajo. 


\section{Bibliografía}

Abbagnano. 1974. Diccionario de Filosofía. México: Fondo de Cultura Económica.

Bessiere, Irene. 2001. "El relato fantástico: Forma mixta de caso y adivinanza”. En: Roas, 28-29.

Bocutti, Anna. 2008. "Humorismo y fantástico en la microficción argentina: Raúl Brasca, Rosalba Campra, Ana María Shua”. Amoxcalli. (1): 223-239.

Boixo, José Carlos (Ed.). 2009. Tendencias de la narrativa mexicana actual. Madrid: Iberoamericana/Vervuert.

Bravo, Víctor Antonio. 1988. La irrupción y el límite. Hacia una reflexión sobre la narrativa fantástica y la naturaleza de la ficción. México: Universidad Nacional Autónoma de México.

Campa Rojas, Lorena. 2006. “La recepción de Alberto Chimal”. En: Gordon (Comp. y Ed.), 67-107.

Canguilhem, Georges. 1976. "La monstruosidad y los monstruos". El conocimiento de la vida. http://es.scribd.com/doc/142312025/Canguilhem-Georges-Lo-monstruosidad-ylo-monstruoso-pdf

Cortázar, Julio. 1989. Historias de cronopios y famas. Buenos Aires: Editorial Sudamericana.

Chimal, Alberto. 2005. "Álbum” y "Conejo". Estos son los días. México: Ediciones Era/ Instituto Nacional de Bellas Artes.

2006. “Introducción”. Viajes Celestes. Cuentos fantásticos del siglo XX. México: Lectorum.

Foucault, Michel. 1980. "Poder- cuerpo" y "La relaciones de poder penetran en los cuerpos". Microfísica del poder. Madrid: Ediciones de La Piqueta.

2005. Vigilar y castigar. Nacimiento de la prisión. México: Siglo Veintiuno Editores. 2011. Los anormales. (Curso en el College de France (1974-1975). Buenos Aires: Fondo de Cultura Económica.

Freud, Sigmund. 1981. "Lo siniestro”. Obras Completas. Tomo III. Madrid: Biblioteca Nueva. García Berrio, Antonio. 1992. Los géneros literarios: Sistema e historia. Madrid: Ediciones Cátedra.

Giddens, Anthony. 2000. Modernidad e identidad del yo. El yo y la sociedad en la época contemporánea. Barcelona: Ediciones Península.

Gordon, Samuel (Comp. y Ed.). 2008. Mito, fantasía y recepción en la obra de Alberto Chimal. México: Ediciones y Gráficos Eón.

Guerra, Lucía. 2006. La mujer fragmentada: Historias de un signo. Chile: Editorial Cuarto Propio.

Herrero Cecilia, Juan. 2000. Estética y pragmática del relato fantástico: Las estrategias narrativas y la cooperación interpretativa del lector. Cuenca: Ediciones de la Universidad de Castilla-La Mancha.

Jackson, Rosemary. 1986. "The Fantastic as a Mode". Fantasy: The Literature of Subversion. Londres: Methuen.

Kristeva, Julia. 1981. El texto de la novela. Barcelona: Editorial Lumen.

León, Fernando de. 2010. "Ver y no ver lo fantástico". En: Crítica. Revista Cultural de la Universidad Autónoma de Puebla. 32 (138). Recuperado de http://revistacritica.com/ vigilia/la-ciudad-imaginada-y-otras-historias-de-alberto-chimal 
Markovic, Ana. 2008. "Lo fantástico y las normas socioculturales”. Amoxcalli. (1): 109-124.

Martínez Cabrera, Erika. 2009. "Silvina Ocampo, fantástica criminal”. En: Montoya y Ángel (Eds.), 129-140.

Montagud López, Elena. 2011. "Lo fantástico y lo siniestro en la narrativa de Silvina Ocampo: los niños”. Ociozero. [artículo de foro]. http://www.ociozero.com/23102/lo-fantasticoy-lo-siniestro-en-la-narrativa-de-silvina-ocampo-los-niños

Montoya Juárez y Esteban Ángel (Eds.). Miradas oblicuas en la narrativa latinoamericana contemporánea. Límites de lo real,fronteras de lo fantástico. Madrid: Iberoamericana/ Vervuert.

Noguerol, Francisca. 2009. "El escalofrío en la última minificción hispánica: Ajuar funerario, de Fernando Iwasaki”. En: Montoya y Ángel (Eds.), 195-218.

Ordiz Vázquez, Javier. 2009. "Incursiones en el reino de lo insólito. Lo fantástico, lo neofantático y lo maravilloso en la narrativa mexicana contemporánea”. En: Boixo (Ed.), 123-142.

Priego, Ernesto. 2010. Alberto Chimal: Lo mejor que hay en todo esto es esa posibilidad de compartir. \#Sin lugar. Espacio ni de aquí ni de allá [Mensaje en un blog]. Recuperado de http://archive.is/35lU

Ramírez, Juan Antonio. 2003. Corpus solus. Para un mapa del cuerpo en el arte contemporáneo. Madrid: Editorial Siruela.

Roas David. 2001. Teorías de lo fantástico. Madrid: Arco.

2011. Tras los límites de lo real. Un definición de lo fantástico. Madrid: Editorial Páginas de Espuma.

Rojo, Violeta. 1995. "El minicuento latinoamericano: modalidad desgenerada". Estudios. Revista de Investigaciones literarias. 3 (6): 65-75.

Sault, Nicole. 1994. "Introduction. The Human Mirror". Many Mirrors. Body Image and Social Relations. U.S.A.: Rutgers, The State University.

Walde, Erna von der. 1996. "Escribir es ordenar.Algunos lugares comunes sobre El Facundo y el quehacer literario en América Latina”. Dissens. http://www.javeriana.edu.co/pensar/ Rev23.html

Zavala, Lauro. 2000. "Seis problemas para la minificción, un género del tercer milenio. Brevedad, Diversidad, Complicidad, Fractalidad, Fugacidad, Virtualidad”. El cuento en Red. http://www.elcuentoenred.org

2011. "Minificción contemporánea. La ficción ultracorta y la literatura posmoderna". (Notas del curso). http://laurozavala.info/attachments/Notas_Miniffin.pdf 